\title{
Robinsoniella peoriensis infection following surgery for scoliosis: a case report
}

\author{
Nadim Cassir ${ }^{1}$, Laurine Laget ${ }^{1}$, Aurélie Renvoisé ${ }^{1}$, Jean-Marie Gennari ${ }^{2}$ and Michel Drancourt ${ }^{1,3 *}$
}

\begin{abstract}
Introduction: Robinsoniella peoriensis was recently identified as a Gram-positive, spore-forming, anaerobic bacillus originally isolated from swine manure storage pits. Seven isolates have been subsequently reported from human sources.

Case presentation: We report the case of an infection caused by R. peoriensis in a 45-year-old Caucasian woman after posterior instrumentation correction of idiopathic thoracolumbar scoliosis. The identification was made by culture of samples inoculated onto blood agar and chocolate agar and was confirmed by $16 \mathrm{~S}$ ribosomal ribonucleic acid gene sequencing.

Conclusions: We discuss similar cases suggesting that $R$. peoriensis is responsible for health care-associated infections with the colonic flora as a potential source of infection.
\end{abstract}

\section{Introduction}

A microbiological survey of swine manure yielded unknown isolates of anaerobic, Gram-positive, non-motile, spore-forming, short oval to rod-shaped bacteria [1]. Six years after the isolation of these unknown Gram-positive anaerobes, a representative isolate was phenotypically and phylogenetically characterized [2]. It was determined that this isolate belonged to the phylum Firmicutes within the family Lachnospiraceae. Phylogenetic analysis showed that this organism belonged to the clostridial ribosomal ribonucleic acid (rRNA) cluster XIVa subgroup, and the closest related genus was Ruminococcus. The organism was named Robinsoniella peoriensis. Since the initial description of this organism from an environmental source, only seven isolates have been reported from human sources [3-5]. We report what is, to the best of our knowledge, the first case of neurosurgical infection caused by $R$. peoriensis and discuss similar cases suggesting that $R$. peoriensis is responsible for health care-associated infections.

\footnotetext{
* Correspondence: michel.drancourt@univmed.fr

${ }^{1}$ Unité de Recherche sur les Maladies Infectieuses et Tropicales Emergentes, UMR CNRS-6236, IRD189, Méditerranée-Infection, Aix-Marseille-Université, 27 Boulevard Jean Moulin, 13005, Marseille, France

${ }^{3}$ Unité de Recherche sur les Maladies Infectieuses et Tropicales Emergentes, Faculté de Médecine, 27, Boulevard Jean Moulin, Marseille cedex 5, France Full list of author information is available at the end of the article
}

\section{Case presentation}

A 45-year-old Caucasian woman was admitted to our hospital for surgical correction of progressive right convex scoliosis. The patient had suffered from an unbalanced adolescent idiopathic thoracolumbar right scoliosis with improvement in adulthood. A preoperative physical examination revealed painful, rigid right thoracolumbar scoliosis and unsupported sitting. A radiograph showed right convex thoracolumbar scoliosis of $68^{\circ}$ with a type IV pelvic obliquity graded according to the classification of King et al. [6]. Her medical history revealed chronic urinary tract infections. She was treated with single-stage scoliosis correction involving posterior instrumentation (Euros spinal system; Euros, La Ciotat, France) from T4 to L5. The spondylodesis was completed by applying allograft bone chips (Etablissement Français du Sang Alpes-Méditerrannée, Tissue Bank, Marseille, France) over the laminae in the thoracolumbar region. Prophylactic cefazolin (1000 mg) was administered intravenously at the induction of anesthesia. At day 8 after the operation, the wound produced negligible clear fluid without any sign of infection and our patient was discharged to a rehabilitation center. At day 16 after the operation, she developed a fever $\left(38.6^{\circ} \mathrm{C}\right)$ and was readmitted to our hospital. A physical examination found an enlarged distal wound dehiscence with increased fluid production. Remarkable laboratory 
parameters included an increased level of C-reactive protein $(65 \mathrm{mg} / \mathrm{L}$; normal is less than $10 \mathrm{mg} / \mathrm{L})$, a white blood cell count of 10.9 cells $\times 10^{9} / \mathrm{L}$ (normal is 4 to 10 cells $\times 10^{9} / \mathrm{L}$ ), and an erythrocyte sedimentation rate of $150 \mathrm{~mm}$ (normal is less than $8 \mathrm{~mm}$ ). A thorough debridement of necrotic tissue and the removal of the bone grafts were performed with the instrumentation left in place. Samples were collected from various deep areas by fluid aspiration and from the applied bone graft. Therapy with three grams of amoxicillin/clavulanate daily was initiated immediately after appropriate intraoperative cultures were obtained.

Three intra-operative specimens were received in the laboratory; direct Gram staining was negative. Samples were inoculated on blood agar and chocolate agar (bioMérieux, Marcy l'Etoile, France) and incubated at $37^{\circ} \mathrm{C}$ both aerobically with $5 \%$ carbon dioxide and anaerobically. All specimens incubated under anaerobic atmosphere yielded positive cultures with tiny, non-hemolytic colonies of Gram-positive rod-shaped bacilli. In vitro susceptibility testing using the disk diffusion method was interpreted in accordance with the guidelines of the Clinical and Laboratory Standards Institute [7]. It indicated susceptibility to amoxicillin/clavulanate, rifampicin, imipenem, metronidazole, clindamycin, and vancomycin and resistance to penicillin G. An attempt was made to identify the isolate by using matrix-assisted laser desorption/ionization time-of-flight mass spectrometry (MALDI-TOF-MS) (Bruker Daltonics, Bremen, Germany). Non-inoculted alpha-cyano-hydroxycinnamic acid matrix was used as a negative control, and positive control consisted of $1.5 \mu \mathrm{L}$ of Bruker Bacterial Test Standard, a protein extract of Escherichia coli DH5alpha. The two negative control spots remained negative, and the two positive control spots identified $E$. coli with score values of 2.281 and 2.363 , thus validating the MALDI-TOF-MS manipulation. The isolate yielded a non-identifying spectrum with identification score values of greater than 1.699. PCR amplification and sequencing yielded a 1466-base pair (bp) $16 \mathrm{~S}$ rRNA gene sequence differing at only 10 nucleotide positions from that of reference $R$. peoriensis (GenBank AF445285; 99.3\% sequence similarity) [2]. In parallel, a 951-bp $16 \mathrm{~S}$ rRNA gene sequence obtained from two patients' specimens as previously reported [8] differed at only three nucleotide positions (similarity of $99.6 \%$ ) from that of $R$. peoriensis reference (GenBank AF445285). Amoxicillin/clavulanate was replaced by a combination of rifampicin $(300 \mathrm{mg}$ ) and clindamycin $(600 \mathrm{mg})$ administered orally at eighthour intervals for six months. Our patient was discharged five days after surgery. Wound healing and temperature were monitored at regular intervals at the out-patient clinic. At three-month follow-up, our patient was afebrile, the wound had healed, and there was no longer biological inflammation. At one-year follow-up, radiographs showed a complete correction of the scoliotic deformity and no instrumentation failure.

\section{Discussion}

We report the first $R$. peoriensis isolate made in our laboratory. We interpreted this isolate as being responsible for the orthopedic device infection in our patient, as it was isolated in pure culture from three different surgical specimens collected at the time our patient had clinical, radiological, and biological evidence of local infection. Also, an $R$. peoriensis-specific $16 \mathrm{~S}$ rRNA gene sequence was detected directly in two specimens. We observed that MALDI-TOF-MS failed to identify the isolate, as $R$. peoriensis profile was not included in its database. This reinforces the usefulness of broad-range PCR for the diagnosis of osteoarticular infections, particularly in case culture-negative infection in which fastidious organisms may be involved [8]. Likewise, the accuracy of $16 \mathrm{~S}$ rRNA gene sequencing for the identification of anaerobic organisms from blood cultures was demonstrated recently [9].

Our patient was cured after the administration of an appropriate antibiotic therapy guided by the results of the in vitro antibiotic susceptibility testing of the isolate. Previous susceptibility testing of four human isolates showed resistance to penicillin (minimal inhibitory concentration, or MIC, of 6 to $8 \mathrm{~g} / \mathrm{mL}$ ) and clindamycin (MIC of 8 to $12 \mathrm{~g} / \mathrm{mL}$ ) but susceptibility to piperacillintazobactam (MICs of $8 / 4$ to $16 / 4 \mathrm{~g} / \mathrm{mL}$ ) and metronidazole (MICs of 0.75 to $1.0 \mathrm{~g} / \mathrm{mL}$ ) [4]. The authors noted that although the isolate from patient three was never tested for antimicrobial susceptibility, the use of clindamycin in this case could have contributed to treatment failure (Table 1). Another isolate was susceptible to metronidazole, cefoxitin, imipenem, amoxicillinclavulanic acid, and piperacillin-tazobactam with MICs of $0.064,8,1,0.5$, and $6 \mathrm{~g} / \mathrm{mL}$, respectively, and was intermediately resistant to clindamycin with an MIC of $4 \mathrm{~g} / \mathrm{mL}$ [3]. Susceptibility testing was performed by using the Etest (AB Biodisk-V, Solna, Sweden) and was interpreted in accordance with the guidelines of the Clinical and Laboratory Standards Institute [7]. Controversially, the case reported by Lopez et al. [5] showed that the isolate tested by Etest was susceptible to penicillin G, amoxicillin/clavulanate, piperacillin/tazobactam, imipenem, metronidazole, and clindamycin. The isolate reported here was susceptible to amoxicillin/clavulanate, rifampicin, imipenem, metronidazole, clindamycin, and vancomycin and resistant to penicillin G. Accordingly, a good outcome has been observed with an association of rifampicin and clindamycinin in the patient reported here. 
Table 1 Case reports of Robinsoniella peoriensis infections

\begin{tabular}{|c|c|c|c|c|c|c|c|c|}
\hline Patient & Sex/Age, years & Sample (delay after admission) & Identification & Underlining condition & Treatment & $\begin{array}{l}\text { Community-acquired } \\
\text { (CA) or health } \\
\text { care-associated (HCA) }\end{array}$ & Outcome & Reference \\
\hline Case 1 & Female/61 & $\begin{array}{l}\text { Left-sided } \\
\text { abdominal fluid } \\
\text { collection }\end{array}$ & $\begin{array}{l}16 \mathrm{~S} \text { rRNA } \\
\text { gene sequencing }\end{array}$ & $\begin{array}{l}\text { Laroscopic sigmoid } \\
\text { colectomy due to } \\
\text { diverticulitis }\end{array}$ & $\begin{array}{l}\text { Percutaneous } \\
\text { drainage } \\
\text { vancomycin } \\
\text { piperacillin-tazobactam } \\
\text { (after unsuccessful } \\
\text { treatment with moxifloxacin } \\
\text { and clindamycin) }\end{array}$ & HCA & Improvement & [4] \\
\hline Case 2 & Female/68 & $\begin{array}{l}\text { Fluid from wound } \\
\text { debridement }\end{array}$ & $\begin{array}{l}16 \mathrm{~S} \text { rRNA } \\
\text { gene sequencing }\end{array}$ & $\begin{array}{l}\text { Open pelvic and } \\
\text { femur fractures }\end{array}$ & $\begin{array}{l}\text { Surgical wound } \\
\text { debridement broad- } \\
\text { spectrum antibiotics }\end{array}$ & CA & Improvement & [4] \\
\hline Case 3 & Male/45 & $\begin{array}{l}\text { Fluid from wound } \\
\text { debridement } \\
\text { (one month) }\end{array}$ & $\begin{array}{l}16 \mathrm{~S} \text { rRNA } \\
\text { gene sequencing }\end{array}$ & $\begin{array}{l}\text { Open reduction and } \\
\text { internal fixation of tibial } \\
\text { and febular fractures }\end{array}$ & $\begin{array}{l}\text { Wound debridement } \\
\text { clindamycin linezolid } \\
\text { (after unsuccessful } \\
\text { treatment with } \\
\text { clindamycin alone) }\end{array}$ & $\mathrm{HCA}$ & Improvement & [4] \\
\hline Case 4 & Female/79 & $\begin{array}{l}\text { Blood cultures } \\
\text { (four days) }\end{array}$ & $\begin{array}{l}16 \mathrm{~S} \text { rRNA } \\
\text { gene sequencing }\end{array}$ & $\begin{array}{l}\text { Coronary artery bypass } \\
\text { surgery for myocardial } \\
\text { infarction,diabetes, } \\
\text { hypertension, and } \\
\text { hypercholesterolemia }\end{array}$ & $\begin{array}{l}\text { Piperacillin/tazobactam, } \\
\text { levofloxacin, and } \\
\text { metronidazole }\end{array}$ & HCA & Died & [4] \\
\hline Case 5 & Female/42 & $\begin{array}{l}\text { Blood cultures } \\
\text { (five days) }\end{array}$ & $\begin{array}{l}16 \mathrm{~S} \text { rRNA } \\
\text { gene sequencing }\end{array}$ & Pancreatic cancer & Metronidazole & HCA & Died & [3] \\
\hline Case 6 & Male/50 & $\begin{array}{l}\text { Muscle hematoma } \\
\text { punction }\end{array}$ & $\begin{array}{l}16 \mathrm{~S} \text { rRNA } \\
\text { gene sequencing }\end{array}$ & Alcoholic liver cirrhosis & $\begin{array}{l}\text { Clindamycin and } \\
\text { ciprofloxacin }\end{array}$ & $\mathrm{HCA}$ & Died & [5] \\
\hline Case 7 & Female/45 & Necrotic tissue & $\begin{array}{l}16 \mathrm{~S} \text { rRNA } \\
\text { gene sequencing }\end{array}$ & $\begin{array}{l}\text { Osteosynthesis for } \\
\text { thoracolumbar scoliosis }\end{array}$ & $\begin{array}{l}\text { Debridement of } \\
\text { necrotic tissue and } \\
\text { removal of the bone } \\
\text { graft clindamycin and } \\
\text { rifampicin }\end{array}$ & HCA & Improvement & Present report \\
\hline
\end{tabular}

rRNA, ribosomal ribonucleic acid. 


\section{Conclusions}

The risk for post-surgical infections and their health care-associated reliability depend on the surgical procedure, which is classified into three categories: clean, clean-contaminated, and contaminated-dirty procedure. Our patient benefited from a clean neurosurgical procedure, and $R$. peoriensis was recovered from surgical specimens concurrently with an enlarged distal wound dehiscence, leading to the diagnosis of a health careassociated infection. Among the seven previously reported human cases of $R$. peoriensis infection, only six had information about the history of infection. Except for one patient who developed $R$. peoriensis soft-tissue infection after open traumatic injury, in which the source of infection remained uncertain [4], and one patient presenting with an infected spontaneous muscular hematoma [4], all cases could be considered health careassociated infections (Table 1). Indeed, previous clinical isolates have been made from the following: the deep wound of the heel of a 79-year-old woman in Sweden without available information [2], one peripheral blood culture of a patient with pancreatic cancer five days after his admission [3], an intra-abdominal fluid collection complicating a laparoscopic colectomy in a 61-year-old woman [4], fluid effusion after wound debridement in a 68-year-old woman with open pelvic and femur fractures with gross soil contamination [4], intra-operative specimens one month after open reduction and internal fixation in a 45-year-old man with right tibial and fibular fractures [4], one blood culture four days after a coronary artery bypass surgery for myocardial infarction in a 79-year-old woman [4], and the punction of an infected spontaneous muscular hematoma in a 50-year-old patient with alcoholic liver cirrhosis [4].

The most common source of anaerobic infections in surgical patients is endogenous normal flora or environmental contamination of wound injuries [10]. Although this anaerobic bacillus has not yet been isolated from normal human flora, the presentation of a case of a post-surgical site infection following a sigmoid colectomy suggests that the source of infection was the disruption of the mucosal barrier [4]. Accordingly, $R$. peoriensis is known to colonize pig feces, indicating it as a colinic organism.

\footnotetext{
Abbreviations

Bp: Base pair; MALDI-TOF-MS: Matrix-assisted laser desorption/ionization time-of-flight mass spectrometry; MIC: Minimal inhibitory concentration; PCR: Polymerase chain reaction; rRNA: Ribosomal ribonucleic acid.
}

Competing interests

The authors declare that they have no competing interests.

\section{Acknowledgments}

This study was funded by Unité de Recherche sur les Maladies Infectieuses et Tropicales Emergentes UMR CNRS-6236, IRD189, IFR48, MéditerranéeInfection, Aix-Marseille-Université, Marseille, France.

\section{Author details}

${ }^{1}$ Unité de Recherche sur les Maladies Infectieuses et Tropicales Emergentes, UMR CNRS-6236, IRD189, Méditerranée-Infection, Aix-Marseille-Université, 27 Boulevard Jean Moulin, 13005, Marseille, France. ${ }^{2}$ Service de Chirurgie Orthopédique, Hôpital Nord, Assistance Publique-Hôpitaux de Marseille, Chemin de Bourrely, 13915, Marseille, France. ${ }^{3}$ Unité de Recherche sur les Maladies Infectieuses et Tropicales Emergentes, Faculté de Médecine, 27, Boulevard Jean Moulin, Marseille cedex 5, France.

\section{Consent}

Written informed consent was obtained from the patient for publication of this manuscript and accompanying images. A copy of the written consent is available for review by the Editor-in-Chief of this journal.

\section{Authors' contributions}

J-MG took care of the patient and helped to analyze and interpret the patient data regarding the hematological disease and the transplant. NC and $\mathrm{LL}$ helped to analyze and interpret the patient data regarding the hematological disease and the transplant. AR helped to perform the microbiological investigations. MD helped to perform the microbiological investigations and was a major contributor in writing the manuscript. All authors read and approved the final manuscript.

Received: 13 February 2012 Accepted: 28 June 2012

Published: 28 June 2012

\section{References}

1. Cotta MA, Whitehead TR, Zeltwanger RL: Isolation, characterization and comparison of bacteria from swine faeces and manure storage pits. Environ Microbiol 2003, 5:737-745.

2. Cotta MA, Whitehead TR, Falsen E, Moore E, Lawson PA: Robinsoniella peoriensis gen. nov., sp. nov., isolated from a swine-manure storage pit and a human clinical source. Int J Syst Evol Microbiol 2009, 59:150-155.

3. Shen D, Chen R, Ye L, Luo Y, Tang YW: Robinsoniella peoriensis bacteremia in a patient with pancreatic cancer. J Clin Microbiol 2010, 48:3448-3450.

4. Gomez E, Gustafson DR, Colgrove R, Ly T, Santana R, Rosenblatt JE, Patel R: Isolation of Robinsoniella peoriensis from four human specimens. J Clin Microbiol 2011, 49:458-460.

5. Lopez P, Belda S, Garcia M, Royo G: Infection of a spontaneous muscular hematoma due to Robinsoniella peoriensis, in a patient with alcoholic liver cirrhosis. Enferm Infecc Microbiol Clin 2010, 28:565-567.

6. King HA, Moe $\mathrm{JH}$, Bradford DS, Winter RB: The selection of fusion levels in thoracic idiopathic scoliosis. J Bone Joint Surg Am 1983, 65:1302-1313.

7. Performance Standards for Antimicrobial Susceptibility Testing of Anaerobic Bacteria; Informational Supplement M11-S1. Chicago, IL: Clinical and Laboratory Standards Institute; 2009

8. Fenollar F, Roux V, Stein A, Drancourt M, Raoult D: Analysis of 525 samples to determine the usefulness of PCR amplification and sequencing of the $16 \mathrm{~S}$ rRNA gene for diagnosis of bone and joint infections. J Clin Microbiol 2006, 44:1018-1028.

9. Fenollar F, Levy PY, Raoult D: Usefulness of broad-range PCR for the diagnosis of osteoarticular infections. Curr Opin Rheumatol 2008, 20:463-470.

10. Edmiston CE Jr, Krepel CJ, Seabrook GR, Jochimsen WG: Anaerobic infections in the surgical patient: microbial etiology and therapy. Clin Infect Dis 2002, 35:S112-S118.

doi:10.1186/1752-1947-6-174

Cite this article as: Cassir et al.: Robinsoniella peoriensis infection following surgery for scoliosis: a case report. Journal of Medical Case Reports 2012 6:174 